\title{
A fixed point theorem for set-valued quasi- contractions in b-metric spaces
}

\author{
Hassen Aydi ${ }^{*}$, Monica-Felicia Bota ${ }^{2}$, Erdal Karapınar ${ }^{3}$ and Slobodanka Mitrović ${ }^{4}$
}

\author{
* Correspondence: hassen. \\ aydi@isima.rnu.tn \\ ${ }^{1}$ Institut Supérieur d'Informatique \\ et des Technologies de \\ Communication de Hammam \\ Sousse, Université de Sousse, Route \\ GP1-4011, Hammam Sousse, \\ Tunisie \\ Full list of author information is \\ available at the end of the article
}

\section{Abstract \\ In this article, we give a fixed point theorem for set-valued quasi-contraction maps in b-metric spaces. This theorem extends, unifies and generalizes several well known comparable results in the existing literature.}

\section{Introduction}

The Banach contraction principle [1] is a very popular tool in solving existence problems in many branches of mathematical analysis. This famous theorem can be stated as follows.

Theorem 1.1. Let $(X, d)$ be a complete metric space and $T$ be a mapping of $X$ into itself satisfying:

$$
d(T x, T y) \leq k d(x, y), \quad \forall x, y \in X,
$$

where $k$ is a constant in $[0,1)$. Then, T has a unique fixed point $x^{*} \in X$.

A mapping $T: X \rightarrow X$ is said to be a quasi-contraction if there exists $0 \leq q<1$ such that for any $x, y \in X$,

$$
d(T x, T y) \leq q \max \{d(x, y), d(x, T x), d(y, T y), d(x, T y), d(y, T x)\},
$$

In 1974, Cirić [2] introduced these maps and proved an existence and uniqueness fixed point theorem.

The study of fixed points for multi-valued contraction maps using the Hausdorff metric was initiated by Nadler [3] in 1969, who extended the Banach contraction principle to set-valued mappings. Since then many authors have studied fixed points for set-valued maps. The theory of set-valued maps has many applications in control theory, convex optimization, differential equations and economics.

Definition 1.1. Let $X$ be any nonempty set. An element $x$ in $X$ is said to be a fixed point of a multi-valued mapping $T: X \rightarrow 2^{X}$ if $x \in T x$, where $2^{X}$ denotes the collection of all nonempty subsets of $X$.

Let $(X, d)$ be a metric space. Let $\mathfrak{C} \mathfrak{B}(X)$ be the collection of all nonempty closed bounded subsets of $X$. For $A, B \in \mathfrak{C} \mathfrak{B}(X)$, define

$$
H(A, B)=\max \{\delta(A, B), \delta(B, A)\},
$$


where

$$
\delta(A, B)=\sup \{d(a, B), \quad a \in A\}, \quad \delta(B, A)=\sup \{d(b, A), \quad b \in B\}
$$

with

$$
d(a, C)=\inf \{d(a, x), x \in C\}, \quad C \in \mathfrak{C} \mathfrak{B}(X) .
$$

Note that $H$ is called the Hausdorff metric induced by the metric $d$.

Definition 1.2. Let $(X, d)$ be a metric space. The set-valued map $T: X \rightarrow \mathfrak{C B}(X)$ is said to be a q-set-valued quasi-contraction if there exists $0 \leq q<1$ such that for any $x$, $y \in X$,

$$
H(T x, T y) \leq q \max \{d(x, y), d(x, T x), d(y, T y), d(x, T y), d(y, T x)\} .
$$

Recently, Amini-Harandi [4] proved a set-valued version of the above mentioned Cirić's theorem [2] as follows:

Theorem 1.2. Let $(X, d)$ be a complete metric space. Suppose that $T: X \rightarrow \mathfrak{C B}(X)$ is said to be a $q$-set-valued quasi-contraction. Assume that $q<\frac{1}{2}$, then $T$ has a fixed point in $X$, that is, there exists $u \in X$ such that $u \in T u$.

In the sequel, the letters $\mathbb{R}_{+}, \mathbb{N}$ and $\mathbb{N}^{*}$ will denote the set of all nonnegative real numbers, the set of all natural numbers and the set of all positive natural numbers, respectively.

Some problems, particularly the problem of the convergence of measurable functions with respect to a measure, lead to a generalization of notion of a metric. Using this idea, Czerwik [5] presented a generalization of the well known Banachs's fixed point theorem [1] in so-called $b$-metric spaces. Consistent with [5,6], we use the following notations and definitions.

Definition 1.3. [6] Let $X$ be a nonempty set and $s \geq 1$ a given real number. A function $d: X \times X \rightarrow \mathbb{R}_{+}$is called a b-metric provided that, for all $x, y, z \in X$,

(bm-1) $d(x, x)=0$,

(bm-2) $d(x, y)=d(y, x)$,

$(\mathrm{bm}-3) d(x, y) \leq s(d(x, z)+d(z, y))$.

Note that a (usual) metric space is evidently a $b$-metric space. However, Czerwik [5,6] has shown that a $b$-metric on $X$ need not be a metric on $\mathrm{X}$ (see also [7-11]. The following example of Singh and Prasad [12] shows that a $b$-metric on $X$ need not be a metric on $X$.

Example 1.4. Let $X=\{0,1,2\}$ and $d(2,0)=d(0,2)=m \geq 2, d(0,1)=d(1,2)=d(0$, $1)=d(2,1)=1$ and $d(0,0)=d(1,1)=d(2,2)=0$. Then,

$$
d(x, y) \leq \frac{m}{2}[d(x, z)+d(z, y)]
$$

for all $x, y, z \in X$. If $m>2$, the ordinary triangle inequality does not hold.

An example of a $b$-metric space was given in [13].

Example 1.5. Let $E$ be a Banach space and $0_{E}$ be the zero vector of $E$. Let $P$ be a cone in $E$ with $\operatorname{int}(P) \neq \varnothing$ and $\leq$ be a partial ordering with respect to $P$. A mapping $d: X \times$ $X \rightarrow E$ is called a cone metric on the nonempty set $X$ if the following axioms are satisfied:

(1) $0_{E} \leq d(x, y)$ for all $x, y \in X$ and $d(x, y)=0_{E}$ if and only if $x=y$; 
(2) $d(x, y)=d(y, x)$, for all $x, y \in X$;

(3) $d(x, y) \leq d(x, z)+d(z, y)$, for all $x, y, z \in X$.

The pair $(X, d)$, where $X$ is a nonempty set and $d$ is a cone metric, is called a cone metric space.

Notice that in [[14], Lemma 5], if the cone $P$ is normal with a constant $K$, then the cone metric $d: X \times X \rightarrow E$ is continuous, i.e. if $\left\{x_{n}\right\},\left\{y_{n}\right\}$ are sequences in $X$ with $x_{n} \rightarrow$ $x$ and $y_{n} \rightarrow y$ as $n \rightarrow \infty$, then $d\left(x_{n}, y_{n}\right) \rightarrow d(x, y)$, as $n \rightarrow \infty$.

Let $E$ be a Banach space and $P$ be a normal cone in $E$ with the coefficient of normality denoted by $K$. Let $D: X \times X \rightarrow \mathbb{R}$ be defined by $D(x, y)=\|d(x, y)\|$, where $d: X \times X \rightarrow E$ is a cone metric space. Then $(X, D)$ is a $b$-metric space with constant $s:=K \geq 1$.

Moreover, since the topology $\tau_{d}$ generated by the cone metric $d$ coincides with the topology $\tau_{D}$ generated by the b-metric D, (see [[15], Theorem 2.4]), the b-metric D is continuous.

Let $(X, d)$ be a $b$-metric space. From now on, we keep the same notations given by (1.2)-(1.4), except that $d$ is a $b$-metric on $X$. We cite the following lemmas from Czerwik $[5,6,9]$ and Singh et al. [11].

Lemma 1.3. Let $(X, d)$ be a b-metric space. For any $A, B, C \in \mathfrak{C} \mathfrak{B}(X)$ and any $x, y \in$ $X$, we have the following:

(i) $d(x, B) \leq d(x, b)$ for any $b \in B$,

(ii) $\delta(A, B) \leq H(A, B)$,

(iii) $d(x, B) \leq H(A, B)$ for any $x \in A$,

(iv) $H(A, A)=0$,

(v) $H(A, B)=H(B, A)$,

(vi) $H(A, C) \leq s(H(A, B)+H(B, C))$,

(vii) $d(x, A) \leq s(d(x, y)+d(y, A))$.

Lemma 1.4. Let $(X, d)$ be a $b$-metric space. Let $A$ and $B$ be in $\mathfrak{C B}(X)$. Then for each $\alpha>0$ and for all $b \in B$ there exists $a \in A$ such that $d(a, b) \leq H(A, B)+\alpha$.

Lemma 1.5. Let $(X, d)$ be a b-metric space. For $A \in \mathfrak{C} \mathfrak{B}(X)$ and $x \in X$, we have

$$
d(x, A)=0 \Leftrightarrow x \in \bar{A}=A .
$$

In this article, we establish the analogous of Theorem 1.2 on a complete $b$-metric space. The main theorem extends several well known comparable results in the existing literature.

\section{Main results}

We start with the following preliminary lemma which we need in the sequel.

Lemma 2.1. [16] Let $(X, d)$ be a b-metric space and $\left\{y_{n}\right\}$ a sequence in $X$ such that

$$
d\left(y_{n+1}, y_{n+2}\right) \leq \gamma d\left(y_{n}, y_{n+1}\right), \quad n=0,1, \ldots,
$$

where $0 \leq \gamma<1$. Then, $\left\{y_{n}\right\}$ is a Cauchy sequence in $X$ provided that $s \gamma<1$.

Let $(X, d)$ be a $b$-metric space. Again as in [4], the set-valued map $T: X \rightarrow \mathfrak{C} \mathfrak{B}(X)$ is said to be a $q$-set-valued quasi-contraction if for any $x, y \in X$,

$$
H(T x, T y) \leq q M(x, y),
$$

where $0 \leq q<1$ and

$$
M(x, y)=\max \{d(x, y), d(x, T x), d(y, T y), d(x, T y), d(y, T x)\} .
$$


Our main result is the following.

Theorem 2.2. Let $(X, d)$ be a complete $b$-metric space. Suppose that $T$ is a q-setvalued quasi-contraction. Assume that $q<\frac{1}{s^{2}+s}$ then $T$ has a fixed point in $X$, that is, there exists $u \in X$ such that $u \in T u$.

Proof. Obviously, $M(x, y)=0$ if and only if $x=y$ is a fixed point of $T$. For the rest, assume that $M(x, y)>0$ for all $x, y \in X$.

Take

$$
\varepsilon=\frac{1}{2}\left(\frac{1}{s^{2}+s}-q\right) \text { and } \beta=q+\varepsilon=\frac{1}{2}\left(\frac{1}{s^{2}+s}+q\right) .
$$

Since we assumed that $q<\frac{1}{s^{2}+s}$, so $\varepsilon>0$ and $0<\beta<1$.

Let $x_{0} \in X$ and $x_{1} \in T x_{0}$. By Lemma 1.4, there must exist $x_{2} \in T x_{1}$ such that

$$
d\left(x_{1}, x_{2}\right) \leq H\left(T x_{0}, T x_{1}\right)+\varepsilon M\left(x_{0}, x_{1}\right) \leq q M\left(x_{0}, x_{1}\right)+\varepsilon M\left(x_{0}, x_{1}\right)=\beta M\left(x_{0}, x_{1}\right) .
$$

Similarly, there exists $x_{3} \in T x_{2}$ such that

$$
d\left(x_{2}, x_{3}\right) \leq H\left(T x_{1}, T x_{2}\right)+\varepsilon M\left(x_{1}, x_{2}\right) \leq q M\left(x_{1}, x_{2}\right)+\varepsilon M\left(x_{1}, x_{2}\right)=\beta M\left(x_{1}, x_{2}\right) .
$$

Thus, by induction there exists a sequence $\left\{x_{n}\right\}$ in $X$ such that $x_{n+1} \in T x_{n}$ and

$$
d\left(x_{n}, x_{n+1}\right) \leq H\left(T x_{n-1}, T x_{n}\right)+\varepsilon M\left(x_{n-1}, x_{n}\right) \leq \beta M\left(x_{n-1}, x_{n}\right) \quad \text { forall } n \in \mathbb{N}^{*} .
$$

Set $d_{n}=d\left(x_{n}, x_{n+1}\right)$. We have

$$
d_{n}=d\left(x_{n}, x_{n+1}\right) \leq \beta M\left(x_{n-1}, x_{n}\right) .
$$

Assume for some $n \in \mathbb{N}, x_{n}=x_{n+1}$, then $x_{n} \in T x_{n}$, so the proof is completed. For the rest, for each $n$ assume that $d_{n} \neq 0$.

On the other hand, for any $n \in \mathbb{N}^{*}$

$$
\begin{aligned}
M\left(x_{n-1}, x_{n}\right) & =\max \left\{d\left(x_{n-1}, x_{n}\right), d\left(x_{n-1}, T x_{n-1}\right), d\left(x_{n}, T x_{n}\right), d\left(x_{n-1}, T x_{n}\right), d\left(x_{n}, T x_{n-1}\right)\right\} \\
& \leq \max \left\{d\left(x_{n-1}, x_{n}\right), d\left(x_{n-1}, x_{n}\right), d\left(x_{n}, x_{n+1}\right), d\left(x_{n-1}, x_{n+1}\right), d\left(x_{n}, x_{n}\right)\right\} \\
& =\max \left\{d_{n-1}, d_{n-1}, d_{n}, d\left(x_{n-1}, x_{n+1}\right), 0\right\} \\
& \leq \max \left\{d_{n-1}, d_{n}, s\left(d_{n-1}+d_{n}\right)\right\} .
\end{aligned}
$$

If for some $n \in \mathbb{N}^{*}, \max \left\{d_{n-1}, d_{n}, s\left(d_{n-1}+d_{n}\right)\right\}=d_{n}$, then from (2.3) we find that $0<$ $d_{n} \leq \beta d_{n}$, which is a contradiction with respect to $0<\beta<1$. We deduce

$$
\max \left\{d_{n-1}, d_{n}, s\left(d_{n-1}+d_{n}\right)\right\}=\max \left\{d_{n-1}, s\left(d_{n-1}+d_{n}\right)\right\} .
$$

Therefore, (2.3) becomes

$$
d_{n} \leq \beta \max \left\{d_{n-1}, s\left(d_{n-1}+d_{n}\right)\right\} .
$$

Put

$$
\gamma=\max \left\{\beta, \frac{s \beta}{1-s \beta}\right\} .
$$

Thus

$$
d_{n} \leq \gamma d_{n-1}, \quad \forall n \in \mathbb{N}^{*} .
$$


Having in mind $s \geq 1, \beta=\frac{1}{2}\left(\frac{1}{s^{2}+s}+q\right)$ and $q<\frac{1}{s^{2}+s}$, so it is easy that

$$
\gamma s<1
$$

Therefore, by (2.4), (2.5) and Lemma 2.1, the sequence $\left\{x_{n}\right\}$ is Cauchy in $(X, d)$. Since the $b$-metric space $(X, d)$ is complete, so there exists $u \in X$ such that

$$
\lim _{n \rightarrow+\infty} d\left(x_{n}, u\right)=0 .
$$

We claim that $u \in T u$, that is, $u$ is a fixed point of $T$. From (2.1), we have

$$
H\left(T x_{n}, T u\right) \leq q M\left(x_{n}, u\right)
$$

where

$$
\begin{aligned}
M\left(x_{n}, u\right) & =\max \left\{d\left(x_{n}, u\right), d\left(x_{n}, T u\right), d(u, T u), d\left(x_{n}, T u\right), d\left(u, T x_{n}\right)\right\} \\
& \leq \max \left\{d\left(x_{n}, u\right), d\left(x_{n}, T u\right), d(u, T u), d\left(x_{n}, T u\right), d\left(u, x_{n+1}\right)\right\}
\end{aligned}
$$

From (2.4), we may write $d_{n} \leq \gamma^{n} d_{0}$ for each $n$. Since $\gamma<1$, we have

$$
\lim _{n \rightarrow+\infty} d_{n}=: d\left(x_{n}, x_{n+1}\right)=0 .
$$

The condition $(\mathrm{rm}-3)$ yields $d\left(x_{n+1}, u\right) \leq s\left(d\left(x_{n+1}, x_{n}\right)+d\left(x_{n}, u\right)\right)$, so

$$
\lim _{n \rightarrow+\infty} d\left(x_{n+1}, u\right)=0 .
$$

Again, by Lemma 1.3, $d\left(x_{n}, T u\right) \leq s\left(d\left(x_{n}, u\right)+d(u, T u)\right.$, then letting $n \rightarrow+\infty$ and using (2.4), we get

$$
\limsup _{n \rightarrow+\infty} d\left(x_{n}, T u\right) \leq s d(u, T u) .
$$

By (2.6)-(2.8), letting $n \rightarrow+\infty$, we get

$$
\limsup _{n \rightarrow+\infty} M\left(x_{n}, u\right) \leq s d(u, T u)
$$

Moreover, since $x_{n+1} \in T x_{n}$, hence $d\left(x_{n+1}, T u\right) \leq H\left(T x_{n}, T u\right)$. Again, because $d(u, T u)$ $\leq s\left(d\left(u, x_{n+1}\right)+d\left(x_{n+1}, T u\right)\right.$, so

$$
\begin{aligned}
\frac{1}{s} d(u, T u) & \leq d\left(x_{n+1}, u\right)+d\left(x_{n+1}, T u\right) \\
& \leq d\left(x_{n+1}, u\right)+H\left(T x_{n}, T u\right) \\
& \leq d\left(x_{n+1}, u\right)+q M\left(x_{n}, u\right) .
\end{aligned}
$$

Letting $n \rightarrow+\infty$ and using (2.4) and (2.9), we find

$$
\frac{1}{s} d(u, T u) \leq q s d(u, T u) .
$$

This leads to

$$
d(u, T u) \leq q s^{2} d(u, T u) .
$$

But, since $q<\frac{1}{s^{2}+s}$, so $q s^{2}<1$, hence $(2.10)$ is true unless $d(u, T u)=0$. From Lemma 1.5, we deduce that $u \in T u$ because that $T u$ is a closed subset in $X$. This completes the proof of Theorem 2.2 .

Remark 2.1. Taking $s=1$ in Theorem 2.2 (it corresponds to the case of metric spaces), the condition on $q$ becomes $q<\frac{1}{2}$, so we find Theorem 1.2 of Amini-Harandi. 
Hence, Theorem 2.2 is an extension of the result of Amini-Harandi [4], which itself improves Theorem 3.3 of Daffer and Kaneko [17] and Corollary 3.3 of Rouhani and Moradi [18].

In 2008, Singh et al. [16] obtained the following result.

Theorem 2.3. Let $(X, d)$ be a complete b-metric space. Take $0<q<1$ and $0<k<1$ with $\alpha=\max \left\{q^{1-k}, \frac{s q^{1-k}}{2-s q^{1-k}}\right\}$. Suppose that $T: X \rightarrow \mathfrak{C B}(X)$ such that

$$
H(T x, T y) \leq q \max \left\{d(x, y), d(x, T x), d(y, T y), \frac{1}{2}[d(x, T y)+d(y, T x)]\right\}
$$

for all $x, y \in X$. Assume that $s q^{1-k}<1$ and $\alpha s<1$. Then, $T$ has a fixed point in $X$, that is, there exists $u \in X$ such that $u \in T u$.

Remark 2.2. Note that

$$
\frac{1}{2}[d(x, T y)+d(y, T x)] \leq \max \{d(x, T y), d(y, T x)\},
$$

so each mapping satisfying (2.11) is also a q-set-valued quasi-contraction. Note that Cirić [19] was the first who studied the contraction (2.11) for single-valued mappings in a metric space. If we take the parameters $0<k<1$ and $0<q<1$ such that

$$
k<\frac{\ln 2}{\ln \left(s^{2}+s\right)} \text { and } q<\frac{1}{s^{2}+s}
$$

it is easy to get $s q^{1-k}<1$ and $\alpha s<1$ where $\alpha$ is given by Theorem 2.3. Therefore, in this case Theorem 2.2 improves Theorem 2.3.

Remark 2.3. Theorem 2.2 is a partial reply to a question proposed by Singh et al. [[16], p. 412].

In the case where $T: X \rightarrow X$ is a $q$-single-valued quasi-contraction on a $b$-metric space, we have the following corollary (it is a consequence of Theorem 2.2).

Corollary 2.4. Let $(X, d)$ be a b-metric space and $T: X \rightarrow X$. Suppose there exists $0 \leq$ $q<1$ such that

$$
d(T x, T y) \leq q \max \{d(x, y), d(x, T x), d(y, T y), d(x, T y), d(y, T x)\} .
$$

Assume that $q<\frac{1}{s^{2}+s^{\prime}}$ then $T$ has a fixed point, that is, there exists $u \in X$ such that $u$ $=T u$.

Proof. It follows by applying Theorem 2.2 and the fact that $H(T x, T y)=d(T x, T y)$ for each $x, y \in X$.

Remark 2.4. Taking $s=1$ in Corollary 2.4, we find the result of Cirić [2].

Now, we give some examples illustrating our results.

Example 2.1. Let $X=0[1]$ and $d(x, y)=|x-y|^{2}$ for all $x, y \in X$. It is obvious that $d$ is a b-metric on $X$ with $s=2$ and $(X, d)$ is complete. Also, $d$ is not a metric on $X$. Define $T: X \rightarrow \mathfrak{C B}(X)$ by

$$
T x=\left\{\begin{array}{cc}
\left\{\frac{1}{2}, \frac{1}{3}\right\} & \text { if } 0 \leq x<1 \\
\left\{\frac{1}{3}\right\} & \text { if } \quad x=1
\end{array}\right.
$$

We shall check that (2.1) is satisfied for all $x, y \in X$. Without loss of generality, take $x$ $\leq y$. If $x=y \in X$ or $x, y \in[0,1)$, then $T x=T y$, so $H(T x, T y)=0$, that is (2.1) holds. Otherwise for all $x<y$, (that is $0 \leq x<1$ and $y=1$ ), standard calculations yield that 


$$
H(T x, T y)=\frac{1}{36} \leq \frac{4}{63}=\frac{1}{7} \cdot \frac{4}{9}=q d(y, T y) \leq q M(x, y)
$$

where $q=\frac{1}{7}<\frac{1}{6}=\frac{1}{s^{2}+s}$ and $M(x, y)$ is given by $(2.2)$.

We deduce that (2.1) holds for all $x, y \in X$. All hypotheses of Theorem 2.2 are satisfied. Here, $\frac{1}{2}$ are $\frac{1}{3}$ are the two fixed points of $T$.

On the other hand, Nadler's Theorem [3] is not applicable for Euclidian metric $d_{0}(x$, $y)=|x-y|$. Indeed, let $H_{0}$ be the Hausdoff metric induced by the metric $d_{0}$. For $x=\frac{5}{6}$ and $y=1$, we have

$$
H_{0}(T x, T y)=\frac{1}{6}>\frac{k}{6}=k d_{0}(x, y) \text { for all } k \in[0,1) .
$$

Also, we couldn't apply Theorem 1.2 (the main result of Amini-Harandi [4]). Indeed, take the metric $D: X \times X \rightarrow[0, \infty)$ given by

$$
D(x, y)= \begin{cases}1 & \text { if } x \neq y \\ 0 & \text { if } x=y\end{cases}
$$

Let $H_{D}$ be the Hausdorff metric induced by the metric D. Again, for $x=\frac{2}{3}$ and $y=1$, we get that

$$
H_{D}(T x, T y)=1>\lambda=\lambda \max \{D(x, y), D(x, T x), D(y, T y), D(x, T y), D(y, T x)\} \text { for all } \lambda \in\left[0, \frac{1}{2}\right) .
$$

Example 2.2. Let $X=[[1], \infty)$ be equipped with the complete b-metric $d(x, y)=\mid x-$ $\left.y\right|^{2}$ for all $x, y \in X,(s=2)$. Define $T: X \rightarrow \mathfrak{C B}(X)$ by $T x=\left[1,1+\frac{x}{3}\right]$ for all $x \in X$. Also, take $q=\frac{1}{9}$. We have

$$
H(T x, T y)=\frac{1}{9}(x-y)^{2}=q d(x, y) \leq q M(x, y),
$$

for all $x, y \in X$, that is (2.1) holds. All hypotheses of Theorem 2.2 are satisfied and $u$ $=1$ is a fixed point of $T$.

\section{Acknowledgement}

The authors would like to express their sincere thanks to the editor and the anonymous referees for their valuable comments and useful suggestions in improving the article. A special thank goes to Professor Stojan Radenović for helping us to finalize Example 2.1. The second author is partially supported by a grant of the Romanian National Authority for Scientific Research, CNCS UEFISCDI, project number PN-II-ID-PCE-2011-3-0094. The fourth author is thankful to the Ministry of Sciences of Republic Serbia.

\section{Author details}

${ }^{1}$ Institut Supérieur d'Informatique et des Technologies de Communication de Hammam Sousse, Université de Sousse, Route GP1-4011, Hammam Sousse, Tunisie ${ }^{2}$ Department of Mathematics, Babeș-Bolyai University, Kogălniceanu Street No.1, 400084, Cluj-Napoca, Romania ${ }^{3}$ Department of Mathematics, Atılım University, İncek, Ankara 06836, Turkey ${ }^{4}$ Department of Mathematics, Faculty of forestry, University of Belgrade, Kneza Viseslava 1, Belgrade, Serbia

\section{Authors' contributions}

All authors contributed equally and significantly in writing this article. All authors read and approve the final manuscript.

\section{Competing interests}

The authors declare that they have no competing interests.

Received: 10 November 2011 Accepted: 22 May 2012 Published: 22 May 2012 


\section{References}

1. Banach, S: Sur les opérations dans les ensembles abstraits et leur application aux équations intégrales. Fund Math. 3 , 133-181 (1922)

2. Ćirić, LB: A generalization of Banach's contraction principle. Proc Am Math Soc. 45, 267-273 (1974)

3. Nadler, SB: Multivalued contraction mappings. Pac J Math. 30, 475-488 (1969)

4. Amini Harandi, A: Fixed point theory for set-valued quasi-contraction maps in metric spaces. Appl Math Lett. 24, 1791-1794 (2011). doi:10.1016/j.aml.2011.04.033

5. Czerwik, S: Contraction mappings in b-metric spaces. Acta Math Inf Univ Ostraviensis. 1, 5-11 (1993)

6. Czerwik, S: Nonlinear set-valued contraction mappings in b-metric spaces. Atti Sem Mat Fis Univ Modena. 46(2), 263-276 (1998)

7. Boriceanu, M: Fixed point theory for multivalued generalized contraction on a set with two b-metrics. Studia Univ Babes-Bolyai Math. LIV(3), 1-14 (2009)

8. Boriceanu, M: Strict fixed point theorems for multivalued operators in b-metric spaces. Int J Modern Math. 4(2), 285-301 (2009)

9. Czerwik, S, Dlutek, K, Singh, SL: Round-off stability of iteration procedures for operators in b-metric spaces. J Nature Phys Sci. 11, 87-94 (1997)

10. Czerwik, S, Dlutek, K, Singh, SL: Round-off stability of iteration procedures for set-valued operators in $b$-metric spaces. J Nature Phys Sci. 11, 87-94 (2007)

11. Singh, SL, Bhatnagar, C, Mishra, SN: Stability of iterative procedures for multivalued maps in metric spaces. Demonstratio Math. 38(4), 905-916 (2005)

12. Singh, SL, Prasad, B: Some coincidence theorems and stability of iterative procedures. Comput Math Appl. 55 2512-2520 (2008). doi:10.1016/j.camwa.2007.10.026

13. Bota, M, Molnar, A, Varga, C: On Ekeland's variational principle in b-metric spaces. Fixed Point Theory. 12(2), 21-28 (2011)

14. Huang, LG, Zhang, X: Cone metric spaces and fixed point theorems of contractive mappings. J Math Anal Appl. 332 1468-1476 (2007). doi:10.1016/j.jmaa.2005.03.087

15. Pavlović, M, Radenović, S, Radojević, S: Abstract metric spaces and Sehgal-Guseman type theorems. Comput Math Appl. $60,865-872(2000)$

16. Singh, SL, Czerwik, S, Krol, K, Singh, A: Coincidences and fixed points points of hybrid contractions. Tamsui Oxford J Math Sci. 24(4), 401-416 (2008)

17. Daffer, PZ, Kaneko, H: Fixed points of generalized contractive Multi-valued mappings. J Math Anal Appl. 192,655-666 (1995). doi:10.1006/jmaa.1995.1194

18. Rouhani, BD, Moradi, S: Common fixed point of multivalued generalized $(\psi, \varphi)$-weak contractive mappings. Fixed Point Theory Appl 2010, 13 (2010). Article ID 708984

19. Ćirić, LB: Fixed points for generalized multi-valued contractions. Math Vesnik. 9(24), 265-272 (1972)

doi:10.1186/1687-1812-2012-88

Cite this article as: Aydi et al:: A fixed point theorem for set-valued quasi-contractions in b-metric spaces. Fixed Point Theory and Applications 2012 2012:88.

\section{Submit your manuscript to a SpringerOpen ${ }^{\circ}$} journal and benefit from:

Convenient online submission

- Rigorous peer review

- Immediate publication on acceptance

- Open access: articles freely available online

- High visibility within the field

- Retaining the copyright to your article

Submit your next manuscript at $\boldsymbol{s p r i n g e r o p e n . c o m ~}$ 